\title{
Induced effects by oxidation with potassium permanganate on the thermal, morphological, colorimetric and pasting properties of corn starch
}

\section{Simone Rosa da Silveira Lazzarotto, Camila Delinski Bet, Polyanna Silveira Hornung, Marcelo Lazzarotto, Egon Schnitzler}

\author{
State University of Ponta Grossa, Ponta Grossa - Paraná, Brazil
}

Keywords:

Starch

Corn

Oxidation

Potassium

permanganate

Article history:

Received 12.02.2017

Received in revised form 01.04.2017

Accepted 23.06.2017

Corresponding

author:

Egon Schnitzler

E-mail:

egons@uepg.br

DOI: $10.24263 / 2304-$

974X-2017-6-2-3

\section{Abstract}

Introduction. Native starches are the most consumed polysaccharides in human diet. They are used in several industries as food, textile, pharmaceutic, etc. However due to some limitations starches should be modified chemically.

Materials and methods. Corn starch modified with standard solutions of potassium permanganate $\left(\mathrm{KMnO}_{4}\right)$ was analysed by simultaneous thermogravimetry-differential thermal analysis, differential scanning calorimetry, rapid viscoamylographic analysis, field emission gun-scanning electron microscopy/energy dispersive spectroscopy, X-ray powder diffraction and colorimetric analysis.

Results and discussion. Corn starch was oxidised with $\mathrm{KMnO}_{4}$ at different concentrations $(0.01 ; 0.02$ and $0.05 \mathrm{~mol}$ $\left.\mathrm{L}^{-1}\right)$ at $\mathrm{pH}=6.0$ for 1 hour. After filtered, washed and dried at $40{ }^{\circ} \mathrm{C}$ by 24 hours, the properties of the samples were investigated. Thermogravimetric curves showed an endothermic peak attributed to evaporation of water and two exothermic peaks, which refer to the decomposition and oxidation of organic matter until the formation of ash. A period of stability was observed, which decrease after modification. The gelatinisation of oxidised starch occurred at higher peak temperatures and also required higher gelatinisation enthalpy. The viscosity of the samples was significantly reduced and the relative crystallinity increased in proportion to the oxidant concentration used. Manganese and potassium content increased with the modification. There were no morphological changes after oxidation; however a darkening of the samples was identified due to the presence of potassium and manganese observed by energy dispersive spectroscopy (EDS).

Conclusions. The obtained fluid paste with low retrogradation tendency suggests the application of oxidised starch in the paper industry.

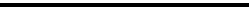




\section{Introduction}

Due to the high productivity and its nutritional importance, corn has become the most cultivated and consumed cereal. It plays an important role as a staple food, especially in less developed countries. Corn flour has a high starch content which can be used in various food and non-food products, such as papers, textiles and pharmaceutical excipients. In the food industry the starch is used to optimize the technological properties, performing functions such as gelling agent, stabilizer, thickener and absorbent $[1,2,3]$.

Numerous researches about starches from different sources have been conducted in order to evaluate its properties and to define its best application. Thus, modifications can be made to suppress limitations and to expand its industrial use, such as the chemical modification by oxidation using potassium permanganate [4].

The main use of oxidised starches is concentrated in the paper industry. This type of modification occurs through the addition of an oxidising agent in the starch in appropriate amounts, under a controlled time, temperature and $\mathrm{pH}$. During the oxidation process, the hydroxyl groups present at C-1, C-2 and C-3 of the starch molecules are initially oxidised to carbonyl groups and then to carboxyl groups, which indicate the degree of oxidation. Parallel to this, there is the breaking of glycoside bonds with partial depolymerisation of starch [5].

The major oxidising agent employed is sodium hypochlorite, but its use is associated with the formation of toxic chlorinated by-products. However, hydrogen peroxide, ammonium persulfate, sodium bromate and potassium permanganate also can be used. The oxidation reaction using permanganate is very complex because it produces free radicals (reduction of $\mathrm{Mn}^{4+}$ to both $\mathrm{Mn}^{3+}$ or $\mathrm{Mn}^{2+}$ ) and/or direct oxidation $[3,6]$.

Many tools are used to evaluate thermal behaviour of starches, as well as thermal analysis $[7,8]$. Thermogravimetry (TG) is a technique that evaluates the mass variation of a sample in function of temperature or time. Differential scanning calorimetry (DSC) measures the heat flow between a sample and a reference material subjected to a temperature change. Through these and some others techniques such as morphological, structural and rheological analysis can be identified changes in the behaviour of the modified starches [9].

Therefore, this study aims the modification of corn starch by oxidation using potassium permanganate $(\mathrm{KMnO} 4)$ at different concentrations $\left(0.01 ; 0.02\right.$ and $\left.0.05 \mathrm{~mol} \mathrm{~L}^{-1}\right)$. The samples were characterised by thermogravimetry and differential thermal analysis (TGDTA), differential scanning calorimetry (DSC); rapid viscoamylographic analysis (RVA); field emission gun/scanning electron microscopy with energy dispersive spectroscopy (FEG-SEM/EDS), X-ray powder diffraction (XRD) and colorimetric analysis.

\section{Materials and methods}

\section{Starch modification}

The native maize starch was bought in Colombo, PR, Brazil and it was divided into four parts of $20 \mathrm{~g}$ (dry basis). One sample (a) was maintained in the native form. The modification was performed according to literature with some modifications [10]. The samples were treated at $\mathrm{pH} 6.0$, for $1 \mathrm{~h}$ with standard potassium permanganate $\left(\mathrm{KMnO}_{4}\right)$ at concentrations of $0.01 \mathrm{~mol} \mathrm{~L}^{-1}$ (b), $0.02 \mathrm{~mol} \mathrm{~L}^{-1}$ (c) $0.05 \mathrm{~mol} \mathrm{~L}^{-1}$ (d). Then the samples were 
washed and filtered until the complete elimination of the oxidising agent. After this, the modified samples were dried in an oven with forced air circulation at $35^{\circ} \mathrm{C}$ for $24 \mathrm{~h}$.

\section{Thermogravimetric study (TG-DTA)}

The TG-DTA curves were obtained using a thermal analysis system (Shimadzu, model DTG-60H). Approximately $6.0-8.0 \mathrm{mg}$ of the samples were heated from $30{ }^{\circ} \mathrm{C}$ to $600{ }^{\circ} \mathrm{C}$ in an open alumina crucibles under a synthetic air flow of $50 \mathrm{~mL} \mathrm{~min}^{-1}$ and a heating rate of $10{ }^{\circ} \mathrm{C} \mathrm{min}^{-1}$. The instrument was previously calibrated with standard weight and monohydrated calcium oxalate standard. All the mass loss percentages were determined using TA-60WS software [11].

\section{Differential scanning calorimetry (DSC)}

The DSC curves were obtained using a thermal analysis system (TA-Instruments, model DSC-Q200, USA). The DSC curves were recorded under an air flow of $50 \mathrm{~mL} \mathrm{~min}^{-1}$ and heating rate of $10^{\circ} \mathrm{C} \mathrm{min}{ }^{-1}$. A suspension with $2.5 \mathrm{mg}$ of the samples in a proportion of 4:1 (water:starch $\mathrm{w} / \mathrm{w}$ ) was prepared in aluminium crucibles which were sealed and left for $1 \mathrm{~h}$ to equilibrate the moisture content. The instrument was previously calibrated with $99.99 \%$ purity Indium, $\mathrm{mp}=156.6^{\circ} \mathrm{C}, \Delta \mathrm{H}=28.56 \mathrm{~J} \mathrm{~g}^{-1}[12]$.

\section{Rapid viscoamylographic analysis (RVA)}

The pasting properties of the samples were obtained using a viscometer (Newport Scientific, model RVA-4, Australia). Suspensions of $3.0 \mathrm{~g}$ of starch in $25.0 \mathrm{~g}$ of distilled water were submitted to a controlled process of heating and cooling under constant stirring, where the samples were held at $50{ }^{\circ} \mathrm{C}$ for two min, heated from 50 to $95{ }^{\circ} \mathrm{C}$ at $6{ }^{\circ} \mathrm{C} \mathrm{min}{ }^{-1}$,

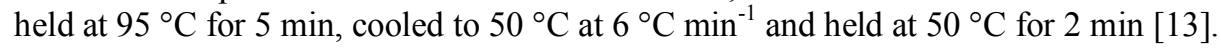

\section{Field emission gun-scanning electron microscopy/Energy dispersive spectroscopy (FEG-SEM/EDS)}

The micro-images of the native and modified samples were obtained using field emission gun-scanning electron microscopy (FEG-SEM) (MIRA 3, Tescan, Czech Republic). The samples were placed on a carbon tape and pulverised with gold and palladium to promote the electrons conductivity. A tension of $20 \mathrm{kV}$ was generated by a lamp with tungsten filament [14]. The chemicals elements present in the samples were identified by EDS, which is based on the released energy measurement when an excited atom (due to electron beam that focuses on the sample) returns to its normal state.

\section{X-ray diffractometry (XRD)}

The X-ray diffraction patterns were obtained using an X-ray diffractometer (Rigaku, model Ultima, Japan), employing $\mathrm{Cu} K \alpha$ radiation $(\lambda=1.541 \AA)$ and settings of $40 \mathrm{kV}$ and $20 \mathrm{~mA}$. An angular range of $5-50^{\circ}(2 \theta)$ with a scanning speed of $8^{\circ} \mathrm{min}^{-1}$ and a step of $0.06^{\circ}$ was used in order to detect the scattered radiation. The degree of relative crystallinity was quantitatively estimated using Eq. 1 and according to the literature [15].

$$
X c=\frac{A_{p}}{A_{p}+A_{b}} \cdot 100
$$

where $X c=$ relative crystallinity; $A_{p}=$ peak area; $A_{b}=$ basis area which refers to amorphous area of diffractogram. 


\section{Colorimetric analysis}

Colour parameters of the starch samples were determined using a reflectance spectrophotometer, model MiniScan XE 45/0-L Plus (Hunter Inc., USA). This technique consists in the evaluation of three colour components: $L^{*}, a^{*}$ and $b^{*}$. The $L^{*}$ parameter correspond to the lightness (from 0, black to 100 , white); $\mathrm{a}^{*}$ indicates the tendency to red $(+)$ and green $(-)$, and $b^{*}$ indicates the tendency to yellow $(+)$ or blue $(-)[11]$.

\section{Statistical analysis}

The analyses were performed in triplicate. All the averages of the samples were analysed by variance analysis (ANOVA) and Tukey's test with a $95 \%$ confidence interval $(\mathrm{p}<0.05)$, using STATISTICA 7.0 software (StatSoft, Inc., Tulsa, OK, USA).

\section{Results and discussion}

\section{Thermogravimetry-Differential thermal analysis (TG-DTA)}

The thermogravimetric curves of the native and treated samples (TG-DTA), Figure 1, presented three main events of mass loss. The first event, which corresponds to the endothermic peak shown by DTA curve, was attributed to evaporation of water and volatile compounds. After this, a period of stability was observed, registering the highest thermal stability for the native sample. The second and third exothermic events refer to the decomposition and oxidation of organic matter until the formation of ash. Similar results were found in the literature $[16,17]$.

The values obtained by TG-DTA curves are shown in Table 1 . The dehydration of the samples occurred in a temperature range from 30 to $150{ }^{\circ} \mathrm{C}$, as reported by Liu et al. [18]. Compared with the centesimal composition analysis, the thermogravimetric method has advantages such as lower mass and time required [19]. The modification by $\mathrm{KMnO}_{4}$ decreased the thermal stability of corn starch to temperatures between $215-249{ }^{\circ} \mathrm{C}$. This may be related to the presence of mono and divalent metal ions complexed with starch granules from anionic groups, such as carboxyl groups formed after the oxidation [20].

The final temperature of decomposition was similar for all the samples $\left(592-599^{\circ} \mathrm{C}\right)$, resulting in $0.7 \%$ ash for native sample and $1.8 ; 3.3$ and $3.5 \%$ for the modified samples (bd), respectively. The increase in the ash content was attributed to the presence of manganese and potassium in the samples due to modification, which was confirmed with EDS analysis. 

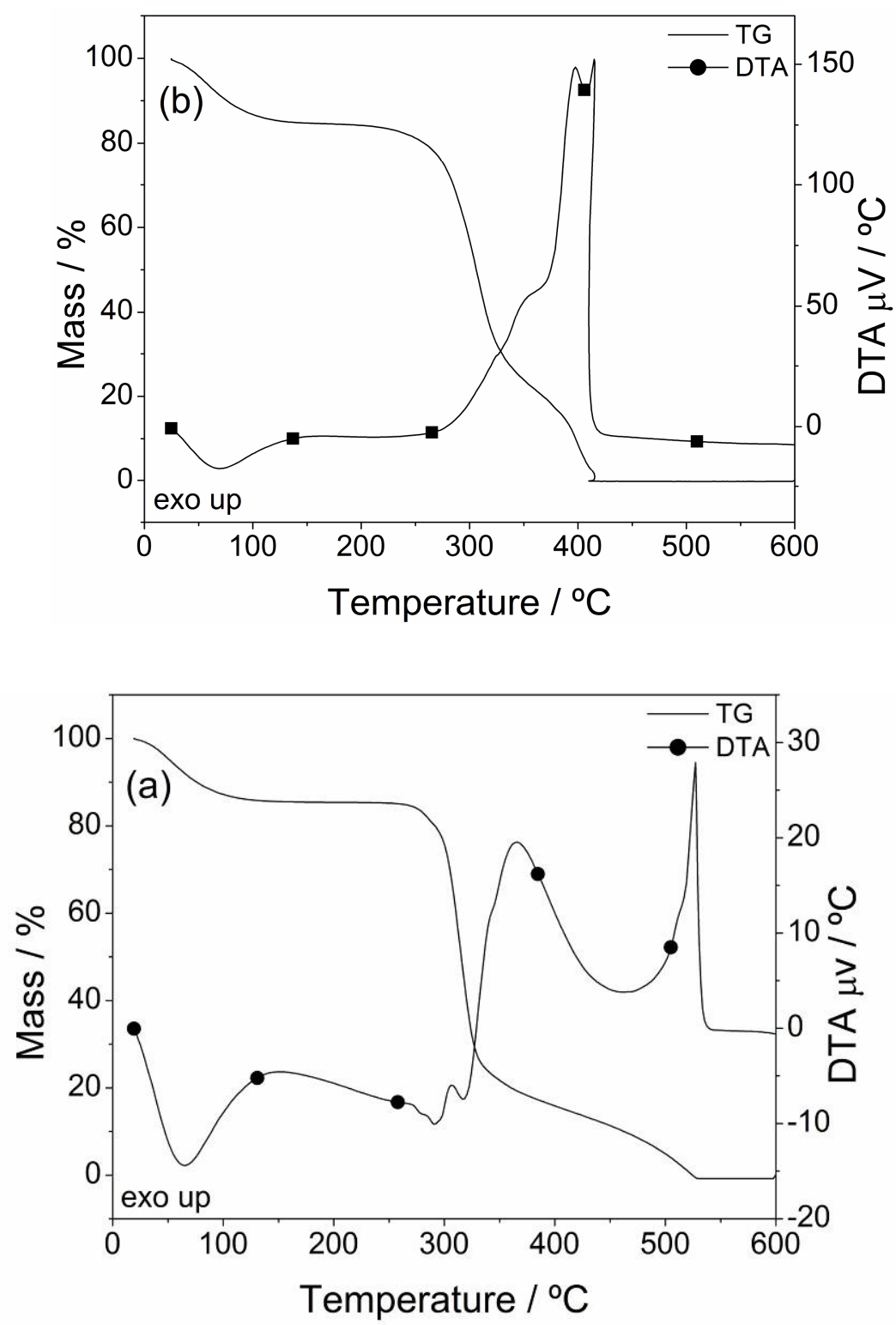

Figure 1. TG-DTA curves for native (a) and modified corn starch with standard $\mathrm{KMnO}_{4}$ at 0.01 $\mathrm{mol} \mathrm{L}^{-1}$ (b); $0.02 \mathrm{~mol} \mathrm{~L}^{-1}$ (c) and $0.05 \mathrm{~mol} \mathrm{~L}^{-1}$ (d)

(Continuation of Figure 1 see on next page) 

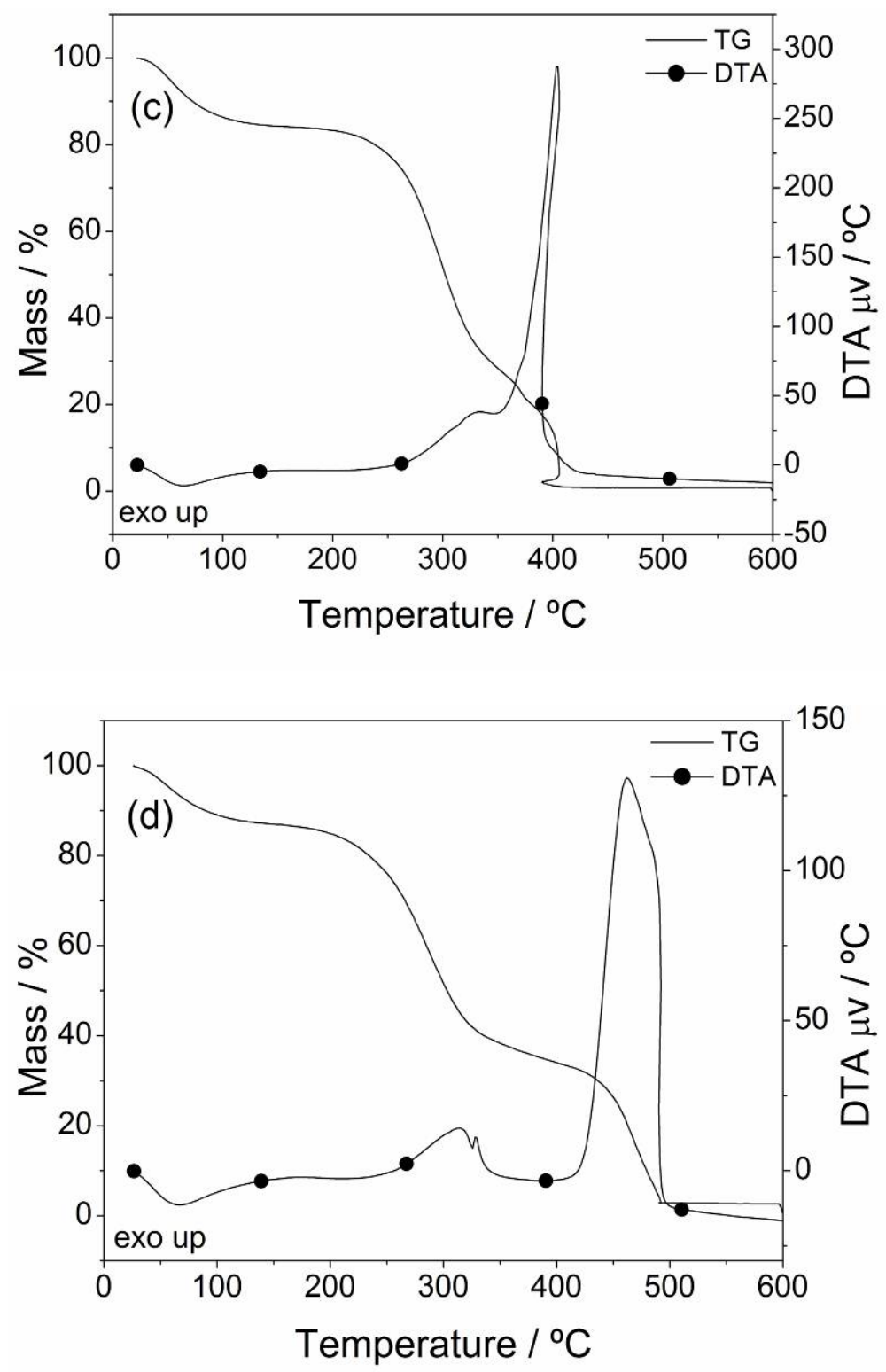

Figure 1 (continuation). TG-DTA curves for native (a) and modified corn starch with standard $\mathrm{KMnO}_{4}$ at $0.01 \mathrm{~mol} \mathrm{~L}^{-1}$ (b); $0.02 \mathrm{~mol} \mathrm{~L}^{-1}$ (c) and $0.05 \mathrm{~mol} \mathrm{~L}^{-1}$ (d) 
Table 1

TG-DTA results for native (a) and modified corn starch with standard $\mathrm{KMnO}_{4}$ at $0.01 \mathrm{~mol} \mathrm{~L}^{-1}$ (b); $0.02 \mathrm{~mol} \mathrm{~L}^{-1}$ (c) and $0.05 \mathrm{~mol} \mathrm{~L}^{-1}$ (d)

\begin{tabular}{|c|c|c|c|c|}
\hline \multirow{2}{*}{ Sample } & \multicolumn{3}{|c|}{ TG Results } & DTA Results \\
\hline & Step & $\Delta m(\%)$ & $\Delta T\left({ }^{\circ} \mathrm{C}\right)$ & $T p\left({ }^{\circ} \mathrm{C}\right)$ \\
\hline \multirow{4}{*}{ (a) } & $1^{\text {st }}$ & 13.3 & $30-158$ & 58.7 (Endo) \\
\hline & Stability & - & $158-249$ & - \\
\hline & $2^{\text {nd }}$ & 71.9 & $249-431$ & 316.3 (Exo) \\
\hline & $3^{\text {rd }}$ & 14.1 & $431-592$ & 512.2 (Exo) \\
\hline \multirow{4}{*}{ (b) } & $1^{\mathrm{st}}$ & 14.5 & $30-159$ & 62.2 (Endo) \\
\hline & Stability & - & $159-224$ & - \\
\hline & $2^{\text {nd }}$ & 61.4 & $224-360$ & 308.6 (Exo) \\
\hline & $3^{\text {rd }}$ & 22.3 & $360-592$ & 397.7 (Ехо) \\
\hline \multirow{4}{*}{ (c) } & $1^{\text {st }}$ & 15.00 & $30-136$ & 67.1 (Endo) \\
\hline & Stability & - & $136-215$ & - \\
\hline & $2^{\text {nd }}$ & 52.8 & $215-346$ & 315.2 (Exo) \\
\hline & $3^{\text {rd }}$ & 28.9 & $346-594$ & $479.2(\mathrm{Exo})$ \\
\hline \multirow{4}{*}{ (d) } & $1^{\mathrm{st}}$ & 12.1 & $30-146$ & 67.5 (Endo) \\
\hline & Stability & - & $146-237$ & - \\
\hline & $2^{\text {nd }}$ & 52.1 & $237-406$ & 313.9 (Exo) \\
\hline & $3^{\text {rd }}$ & 32.3 & $406-59$ & 462.3 (Еxo) \\
\hline
\end{tabular}

$\Delta \mathrm{m}$, mass loss $(\%) ; \Delta \mathrm{T}$, temperature range $\left({ }^{\circ} \mathrm{C}\right)$; Tp, peak temperature $\left({ }^{\circ} \mathrm{C}\right)$.

\section{Gelatinisation study}

DSC was used to evaluate the gelatinisation of native and oxidised samples. The transition in the curves (Figure 2) corresponds to the dissociation of the amylose and amylopectin molecules within the starch granules and leaching out of amylose to the continuous phase, characteristic of gelatinisation process [21]. There was a slight shift to the right in the endothermic event for the samples (b) and (c) in relation to the sample (a).

The results in Table 2 of native and oxidised starches were similar to those obtained by Liu et al. [22]. The oxidised samples (b) and (c) had a higher onset temperature $\left(\mathrm{T}_{\mathrm{o}}\right)$ than the native sample (a). The sample modified with the highest concentration of $\mathrm{KMnO}_{4}$ presented the lowest value for the onset temperature $\left(\mathrm{T}_{\mathrm{o}}\right)$. The peak temperatures of modified starches were higher than the native sample, as well as the gelatinisation enthalpy $\left(\Delta \mathrm{H}_{\text {gel }}\right)$ values. It was suggested that this occur due to hydrolysis in the amorphous lamella, resulting in the increased of

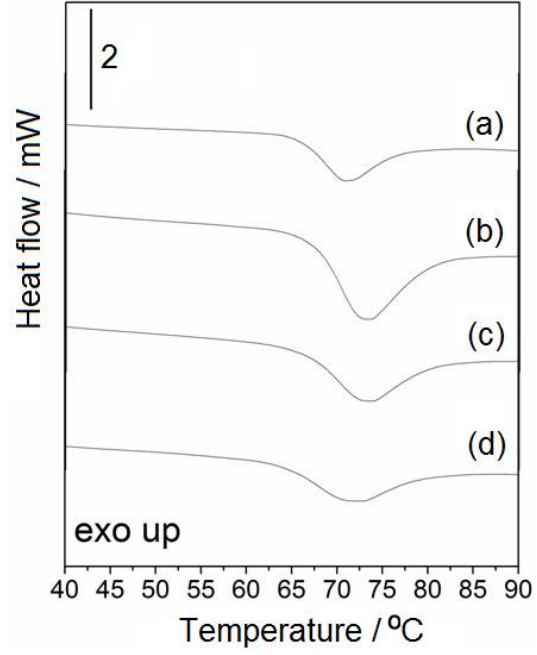

Figure 2. DSC curves to the gelatinisation phenomenon for native (a) and modified corn starch with standard $\mathrm{KMnO}_{4}$ at $0.01 \mathrm{~mol} \mathrm{~L}^{-1}$ (b); $0.02 \mathrm{~mol} \mathrm{~L}^{-1}$ (c) and $0.05 \mathrm{~mol} \mathrm{~L}^{-1}$ (d) 
the hydration and swelling of starch crystallites, disrupting the crystalline lamella. Thus, a highest temperature was necessary to oxidised starch gelatinisation [23]. Conclusion temperature $\left(T_{c}\right)$ decreased significantly for the samples $(a, b, c)$.

Table 2

DSC gelatinisation results for native (a) and modified corn starch with standard $\mathrm{KMnO}_{4}$ at $0.01 \mathrm{~mol} \mathrm{~L}^{-1}(\mathrm{~b}) ; 0.02 \mathrm{~mol} \mathrm{~L}^{-1}$ (c) and $0.05 \mathrm{~mol} \mathrm{~L}^{-1}(\mathrm{~d})$

\begin{tabular}{|c|c|c|c|c|}
\hline \multirow{2}{*}{ Sample } & \multicolumn{4}{|c|}{ DSC gelatinisation } \\
\cline { 2 - 5 } & $\left.\boldsymbol{T}_{\boldsymbol{o}} \boldsymbol{\rho}^{\mathbf{0}} \mathbf{C}\right)^{\mathrm{a}}$ & $\left.\boldsymbol{T}_{\boldsymbol{p}} \mathbf{(}^{\mathbf{o}} \mathbf{C}\right)$ & $\boldsymbol{T}_{\boldsymbol{c}}\left({ }^{\mathbf{o}} \mathbf{C}\right)$ & $\boldsymbol{\Delta} \boldsymbol{H}_{\text {gel }}\left(\mathbf{J ~ J ~ g}^{-\mathbf{1}}\right)$ \\
\hline $\mathbf{( a )}$ & $66.1 \pm 0.15^{\mathrm{b}}$ & $70.8 \pm 0.05^{\mathrm{c}}$ & $83.2 \pm 1.96^{\mathrm{a}}$ & $7.3 \pm 0.33^{\mathrm{c}}$ \\
\hline (b) & $67.7 \pm 0.03^{\mathrm{a}}$ & $73.0 \pm 0.14^{\mathrm{a}}$ & $79.7 \pm 1.11^{\mathrm{b}}$ & $13.1 \pm 0.17^{\mathrm{a}}$ \\
\hline (c) & $66.4 \pm 0.41^{\mathrm{b}}$ & $73.0 \pm 0.04^{\mathrm{a}}$ & $79.7 \pm 1.46^{\mathrm{b}}$ & $10.4 \pm 1.61^{\mathrm{b}}$ \\
\hline (d) & $63.8 \pm 0.33^{\mathrm{c}}$ & $71.0 \pm 0.04^{\mathrm{b}}$ & $79.3 \pm 1.00^{\mathrm{b}}$ & $9.4 \pm 0.80^{\mathrm{b}}$ \\
\hline
\end{tabular}

$T_{o}$ "onset" initial temperature, $T p$ peak temperature, $T_{c}$ "endset" conclusion temperature, $\Delta H_{\text {gel }}$ gelatinisation enthalpy. Values followed by the same letter in the same column are not significantly different by Tukey's test $(\mathrm{p}<0.05)$.

\section{Pasting properties (RVA)}

The RVA curves are shown in Figure 3. Oxidation of starch with potassium permanganate caused a reduction in the viscosity peak of the samples. This reduction can be attributed to degradation of the starch chains caused by oxidation, with consequent reduction of the molecular weight [24]. This type of starch can be used in the batter applications because it promotes a higher binding and stability[23].

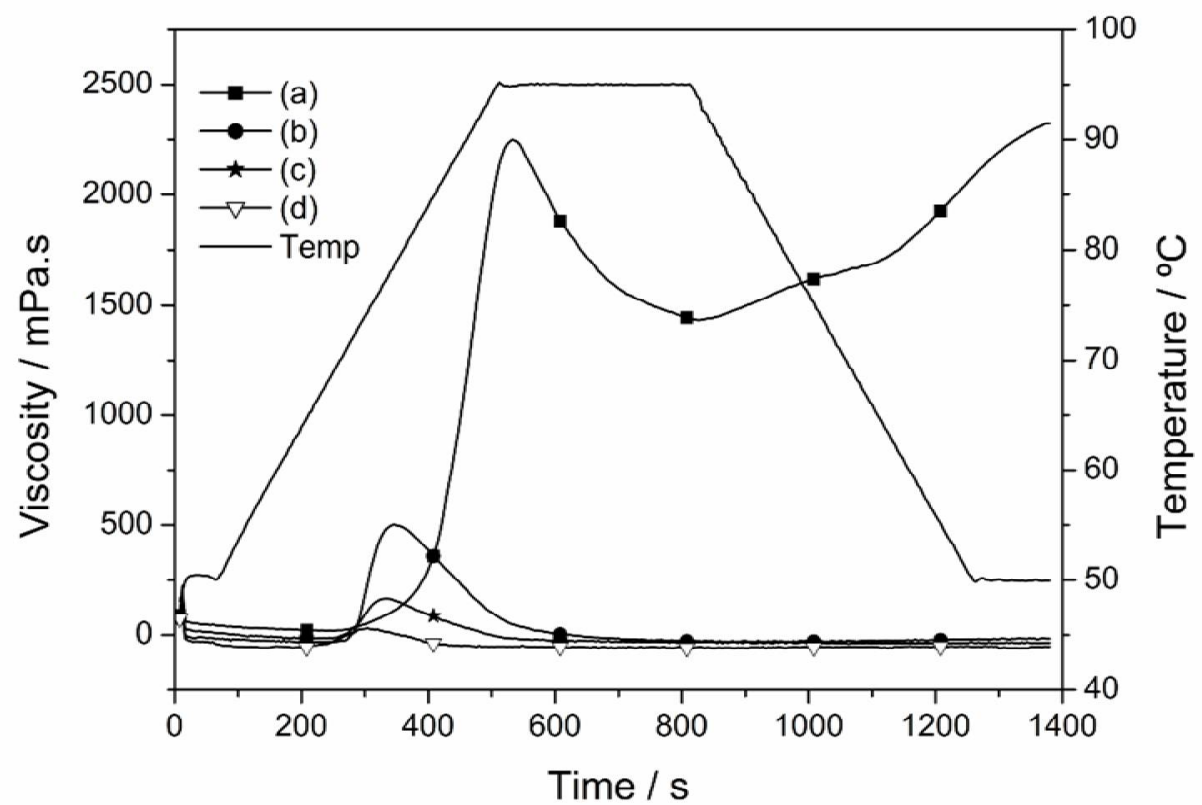

Figure 3. RVA curves for native (a) and modified corn starch with standard $\mathrm{KMnO}_{4}$ at $0.01 \mathrm{~mol} \mathrm{~L}^{-1}(\mathrm{~b}) ; 0.02 \mathrm{~mol} \mathrm{~L}^{-1}$ (c) and $0.05 \mathrm{~mol} \mathrm{~L}^{-1}($ d) 
There was significant difference between the samples for all the parameters. The lowest value for the peak viscosity (Table 3) was observed to the sample (d), modified with the highest concentration of $\mathrm{KMnO}_{4}$. It was not possible to determine the pasting temperature for the sample (d), probably due to the low peak viscosity value. The sample (b) presented a significant reduction in this parameter.

Since there was a major disruption of the starch chains by the modification, there was no reassociation of amylose chains during cooling the starch slurry (setback), which can also be confirmed by the low values of final viscosity recorded.

Table 3

RVA results for native (a) and modified corn starch with standard $\mathrm{KMnO}_{4}$ at $0.01 \mathrm{~mol} \mathrm{~L}^{-1}$ (b); $0.02 \mathrm{~mol} \mathrm{~L}^{-1}(\mathrm{c})$ and $0.05 \mathrm{~mol} \mathrm{~L}^{-1}(\mathrm{~d})$

\begin{tabular}{|c|c|c|c|c|c|c|}
\hline Sample & $\begin{array}{c}\text { Pasting } \\
\text { temperature } \\
\left.\mathbf{(}^{\mathbf{0}} \mathbf{C}\right)\end{array}$ & $\begin{array}{c}\text { Viscosity } \\
\text { peak } \\
(\mathbf{m P a . s})\end{array}$ & $\begin{array}{c}\text { Setback } \\
\text { (mPa.s) }\end{array}$ & $\begin{array}{c}\text { Breakdown } \\
\text { (mPa.s) }\end{array}$ & $\begin{array}{c}\text { Final } \\
\text { viscosity } \\
\text { (mPa.s) }\end{array}$ & $\begin{array}{c}\text { Peak } \\
\text { time (s) }\end{array}$ \\
\hline \multirow{2}{*}{ (a) } & $82.5 \pm$ & $2246.3 \pm$ & $889.8 \pm$ & $814.9 \pm$ & $2323.7 \pm$ & $82.5 \pm$ \\
& $0.02^{\mathrm{a}}$ & $1.53^{\mathrm{a}}$ & $0.38^{\mathrm{a}}$ & $0.15^{\mathrm{a}}$ & $0.58^{\mathrm{a}}$ & $0.02^{\mathrm{a}}$ \\
\hline (b) & $71.8 \pm$ & $499.7 \pm$ & $15.0 \pm$ & $533.2 \pm$ & $-17.0 \pm$ & $71.8 \pm$ \\
& $0.02^{\mathrm{c}}$ & $1.53^{\mathrm{b}}$ & $0.01^{\mathrm{b}}$ & $0.21^{\mathrm{b}}$ & $0.01^{\mathrm{b}}$ & $0.02^{\mathrm{c}}$ \\
\hline \multirow{2}{*}{ (c) } & $73.6 \pm$ & $165.7 \pm$ & $5.0 \pm$ & $205.2 \pm$ & $-35.4 \pm$ & $73.6 \pm$ \\
& $0.01^{\mathrm{b}}$ & $1.15^{\mathrm{c}}$ & $0.02^{\mathrm{d}}$ & $0.15^{\mathrm{c}}$ & $0.53^{\mathrm{c}}$ & $0.01^{\mathrm{b}}$ \\
\hline \multirow{2}{*}{ (d) } & - & $28.3 \pm$ & $7.0 \pm$ & $90.0 \pm$ & $-53.9 \pm$ & - \\
& & $1.53^{\mathrm{d}}$ & $0.01^{\mathrm{c}}$ & $0.20^{\mathrm{d}}$ & $1.00^{\mathrm{d}}$ & - \\
\hline
\end{tabular}

$\mathrm{mPa}$ s "millipascal-second", s "second". Values followed by the same letter in the same column are not significantly different by Tukey's test $(\mathrm{p}<0.05)$.

\section{Morphology and determination of metallic ions}

The micro-images of the starch granules obtained using field emission gun-scanning electron microscopy are showed in Figure 4. A polyhedral and irregular shape with flat surface was observed for corn starch, as found in the literature [9]. There was no change in the morphology of the granules after modification, as obtained by Zhou et al. [25] after oxidation of potato starch at low concentrations of sodium hypochlorite. Other studies reported the appearance of pores on the surface of the starch granules after the oxidation under alkaline conditions, which was not observed in this study [26].

The average diameter of the untreated and treated maize starch granules was calculated and its results are presented in Table 4. There was no significant difference between the average diameter values, although a decrease can be observed with increasing concentration of the oxidising agent. 

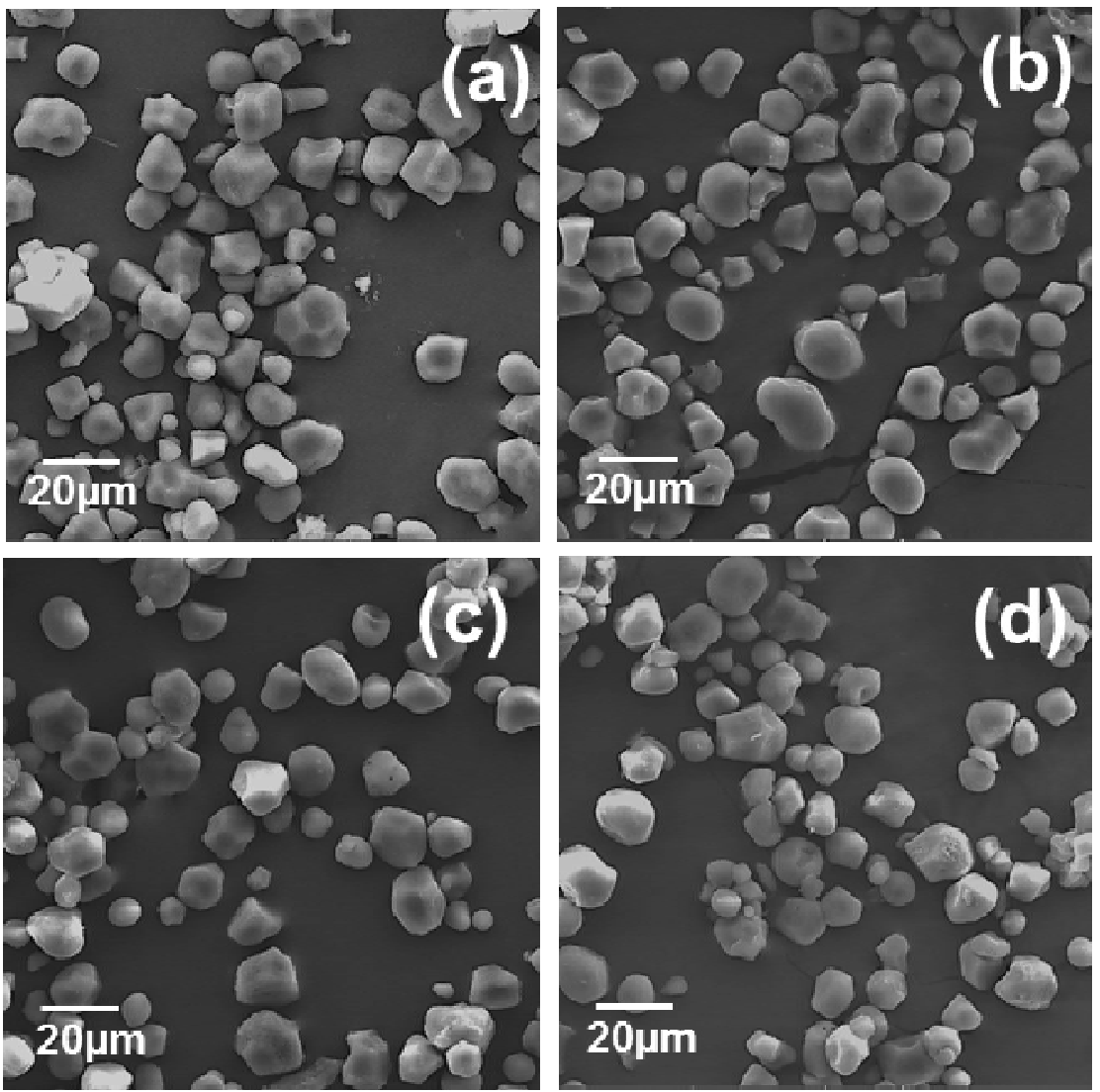

Figure 4. FEG images for native (a) and modified corn starch with standard $\mathrm{KMnO}_{4}$ at $0.01 \mathrm{~mol} \mathrm{~L}^{-1}(\mathrm{~b}) ; 0.02 \mathrm{~mol} \mathrm{~L}^{-1}$ (c) and $0.05 \mathrm{~mol} \mathrm{~L}^{-1}(\mathrm{~d})$

Table 4

FEG-EDS and XRD results and Colour parameters for native (a) and modified corn starch with standard $\mathrm{KMnO}_{4}$ at $0.01 \mathrm{~mol} \mathrm{~L}^{-1}(\mathrm{~b}) ; 0.02 \mathrm{~mol} \mathrm{~L}^{-1}$ (c) and $0.05 \mathrm{~mol} \mathrm{~L}^{-1}$ (d)

\begin{tabular}{|c|c|c|c|c|c|c|}
\hline \multirow{2}{*}{ Samples } & \multicolumn{3}{|c|}{ FEG-EDS } & \multicolumn{3}{c|}{ Colour parameters } \\
\cline { 2 - 7 } & $\begin{array}{c}\mathrm{K} / \mathrm{Pd} \\
(\mathrm{wt} \%)\end{array}$ & $\begin{array}{c}\mathrm{Mn} / \mathrm{Pd} \\
(\mathrm{wt} \%)\end{array}$ & $\mathrm{d}_{\mathrm{a}}(\mu \mathrm{m})$ & $\mathrm{L}^{*}$ & $\mathrm{a}^{*}$ & $\mathrm{~b}^{*}$ \\
\hline \multirow{2}{*}{ (a) } & N. D. & N. D. & $\begin{array}{c}13.9 \pm \\
0.77^{\mathrm{a}}\end{array}$ & $\begin{array}{c}93.2 \pm \\
3.0^{\mathrm{a}}\end{array}$ & $\begin{array}{c}-0.8 \pm \\
0.1^{\mathrm{d}}\end{array}$ & $3.3 \pm 0.8^{\mathrm{d}}$ \\
\hline \multirow{2}{*}{ (b) } & $27.8 \pm$ & $53.4 \pm$ & $13.1 \pm$ & $54.6 \pm$ & $6.0 \pm$ & $26.0 \pm$ \\
& $0.12^{\mathrm{a}}$ & $6.18^{\mathrm{a}}$ & $0.49^{\mathrm{ab}}$ & $0.19^{\mathrm{b}}$ & $0.07^{\mathrm{c}}$ & $0.30^{\mathrm{b}}$ \\
\hline \multirow{2}{*}{ (c) } & $30.6 \pm$ & $57.5 \pm$ & $12.6 \pm$ & $43.2 \pm$ & $8.2 \pm$ & $28.3 \pm$ \\
& $1.82^{\mathrm{b}}$ & $0.24^{\mathrm{a}}$ & $0.54^{\mathrm{ab}}$ & $0.15^{\mathrm{c}}$ & $0.02^{\mathrm{b}}$ & $0.19^{\mathrm{a}}$ \\
\hline \multirow{2}{*}{ (d) } & $33.7 \pm$ & $61.6 \pm$ & $12.1 \pm$ & $27.7 \pm$ & $9.4 \pm$ & $22.7 \pm$ \\
& $0.86^{\mathrm{b}}$ & $4.46^{\mathrm{a}}$ & $0.34^{\mathrm{b}}$ & $0.21^{\mathrm{d}}$ & $0.11^{\mathrm{a}}$ & $0.43^{\mathrm{c}}$ \\
\hline
\end{tabular}

FEG-EDS: weight ratio of potassium and manganese; $\mathrm{d}_{\mathrm{a}}$ : average diameter. Values followed by different letters in the same column present significant difference according to Tukey's test $(p<0.05)$. 
Through EDS it was possible to measure some chemical elements present in the samples (Figure 4). The identified elements were manganese and potassium, which were derived from the oxidation of starch with potassium permanganate. The palladium was added by the metallisation process that is required for FEG analysis. As the metallisation time was similar for all the samples, it was considered as a constant the palladium content and it was calculated the relative presence of manganese and potassium on the modified samples, since there was no presence of these elements in the native sample. The concentrations are presented in Table 4. With increasing of $\mathrm{KMnO}_{4}$ concentration it were observed an increase of the manganese and potassium concentration in the oxidised samples.

\section{X-ray powder diffraction (XRD)}

X-ray diffractograms for each sample are shown in Figure 5. According to the literature [27], starch diffraction patterns are related with the main peaks obtained by XRD. Therefore, when the starch presents peaks at $15 ; 17 ; 18$ and $23^{\circ}(2 \theta)$, it can be classified as A-type. B-type presents peaks at 5.6;15;17; 18 and $23^{\circ}$, and C-type shows peaks at 5.5; 15; $17 ; 22$ and $23^{\circ}$, which is considered a mixture of $\mathrm{A}$ and $\mathrm{B}$ types. The native and modified corn starches presented the most intense peaks at $15^{\circ} ; 17^{\circ} ; 18^{\circ}$ and $23^{\circ}(2 \Theta)$; therefore, the diffraction pattern was classified as A-type, which is characteristic for starches derived of cereals [28].

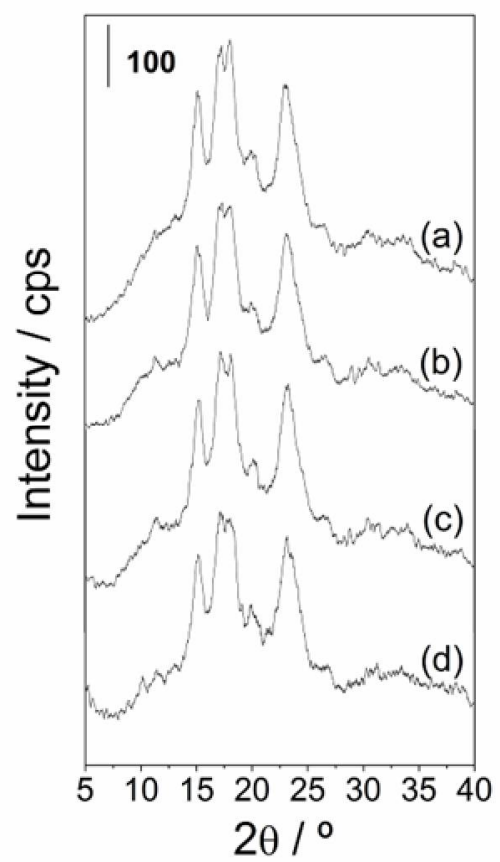

Figure 5. X-ray diffraction for native (a) and modified corn starch with standard $\mathrm{KMnO}_{4}$ at $0.01 \mathrm{~mol} \mathrm{~L}^{-1}(\mathrm{~b}) ; 0.02 \mathrm{~mol} \mathrm{~L}^{-1}(\mathrm{c})$ and $0.05 \mathrm{~mol} \mathrm{~L}^{-1}(\mathrm{~d})$

The relative crystallinity values calculated for the samples were: (a) $30.68 \pm 0.36^{c}$; (b) $36.56 \pm 0.24^{\mathrm{b}}$; (c) $36.92 \pm 0.66^{\mathrm{b}}$ and (d) $42.62 \pm 0.17^{\mathrm{a}}$. Analysing these values, an increase in this parameter was observed for the modified samples, with significant difference 


\section{- Food Technology -}

between themselves, except between the samples (b) and (c). Similar results were reported by Zhou et al. [25] for potato starch treated with sodium hypochlorite at low concentrations, suggesting that oxidation reactions occur mainly in the amorphous regions of the granule.

\section{Colorimetric parameters}

The colorimetric parameters are shown in Table 4 . The results corroborate the changes that can be observed visually in the modified starch samples. A significant decrease was identified in the $\mathrm{L}^{*}$ parameter for the oxidised starches (b-d) in relation to the native (a), which showed a greater tendency to black proportionally to concentration of potassium permanganate used.

When the samples were treated, a tendency to red and to yellow was observed by the $a^{*}$ and $b^{*}$ parameters, respectively. This darkening of the samples can be attributed to the action of the oxidising agent in the starch structure. Similar results were reported by Pietrzyk et al. [20].

\section{Conclusions}

Corn starch was investigated after oxidation with potassium permanganate at different concentrations.

The TG-DTA analysis showed a highest thermal stability for the native sample. DSC curves presented higher peak temperature and the gelatinisation enthalpy $\left(\Delta \mathrm{H}_{\text {gel }}\right)$ values for the modified samples.

There was a considerable reduction in peak viscosity of the oxidised samples with potassium permanganate proportional to the concentration used.

It was detected an increase in the manganese and potassium content for the modified starches by EDS.

All the samples showed A-type diffraction pattern and the degree of relative crystallinity was lower for the native sample.

A decrease in the $\mathrm{L}$ parameter and a higher tendency to red and yellow were identified for the oxidised corn starches, resulting in the darkening of them.

Therefore, the modification with potassium permanganate promoted strong changes in the properties of corn starch. This process can be used to modified the characteristics of native corn starch as alternative for others oxidising agents, such as sodium hypochlorite which is associated with the formation of toxic compounds. Besides, the obtained fluid paste with low retrogradation tendency suggests the application of oxidised starch in the paper industry.

Acknowledgements. The authors would like to thank the Brazilian organization CAPES and CNPq for the financial support and also to thank CLABMU (UEPG) for help in the analysis. 


\section{References}

1. Uarrota V.G., Amante E.R., Demiate I.M., Vieira F., Delgadillo I., Maraschin M. (2013), Physicochemical, thermal, and pasting properties of flours and starches of eight Brazilian maize landraces (Zea mays L.), Food Hydrocolloid, 30, pp. 614-624.

2. Neelam K., Viajay S., Lalit S. (2012), Various techniques for the modification of starch and the application of its derivatives, Int. Res. J. Pharm, 3, pp. 25-31.

3. Adebooye O.C., Singh V. (2008), Physico-chemical properties of the flours and starches of two cowpea varieties (Vigna unguiculata (L.) Walp), Innovative Food Sci. Emerging Technol., 9, pp. 92-100.

4. Hebeish A., El-Rafie M.H., El-Sisi F., Abdel Hafiz F., Abdel-Rahman A.A. (1994), Oxidation of maize and rice starches using potassium permanganate with various reductants, Polym. Degrad. Stab., 43, pp. 363-372.

5. Halal S.L.M., Colussi R., Pinto V.Z., Bartz J., Radunz M., Carreño N.L.V., Dias, A.R.G., Zavareze E.R. (2015), Structure, morphology and functionality of acetylated and oxidised barley starches, Food Chem., 168, pp. 247-256.

6. Hornung P.S., Oliveira C.S., Lazzarotto M., Lazzarotto S.R.S., Schnitzler E. (2015a), Investigation of the photo-oxidation of cassava starch granules, Therm. Anal. Calorim, 123, pp. 2129-2137.

7. Hornung P.S., Granza A.G., Oliveira C.S., Lazzarotto M., Schnitzler E. (2015b), Study of the Effects of Ultraviolet Light and Sodium hypochlorite Solutions on Properties of Cassava Starch Granules, Food Biophys, 10, pp. 368-374.

8. Ribeiro L.S., Cordoba L.P., Colman T.A., Oliveira C.S., Andrade M.M.P., Schnitzler E. (2014), Influence of some sugars on the thermal, rheological and morphological properties of "pinhão" starch, J.Therm. Anal. Calorim., 117, pp. 935-942.

9. Malucelli L.C., Lacerda L.G., Carvalho Filho M.A.S., Fernández D.E.R., Demiate I.M., Oliveira C.S., Schnitzler, E. (2015), Porous waxy maize starch, J. Therm. Anal. Calorim., 120, pp. 525-532.

10. Dias A.R.G., Zavareze R., Helbig E., Moura F.A., Vargas C.G., Ciacco C.F. (2011), Oxidation of fermented cassava starch using hydrogen peroxide, Carbohydr. Polym., 86, pp. 185-191.

11. Colman T.A.D., Demiate I.M., Schnitzler E. (2014), The effect of microwave radiation on some thermal, rheological and structural properties of cassava starch, J. Therm. Anal. Calorim., 115, pp. 2245-2252

12. Beninca C., Colman T.A.D., Lacerda L.G., Carvalho-Filho M.A.S., Demiate I.M., Schnitzler E. (2013), Thermal, rheological, and structural behaviors of natural and modified cassava starch granules, with hypochlorite solutions, J. Therm. Anal. Calorim., 111, pp. 2217-2222.

13. Andrade M.M.P., Oliveira C.S., Colman T.A.D., Costa F.J.O.G., Schnitzler E. (2014), Effects of heat-moisture treatment on organic cassava starch, J. Therm Anal. Calorim., 115, pp. 2115-2122.

14. Bet C.D., Cordoba L.P., Ribeiro L.S., Schnitzler E. (2016), Common vetch (Vicia sativa) as a new starch source: its thermal, rheological and structural properties after acid hydrolysis, Food Biophys, 11, pp. 275-282.

15. Zhang L., Xie W., Zhao X., Liu Y., Gao W. (2009), Study on the morphology, crystalline structure and thermal properties of yellow ginger starch acetates with different degrees of substitution, Thermochim. Acta, 495, pp. 57-62.

16. Oliveira C.S., Andrade M.M.P., Colman T.A.D., Costa F.J.O.G., Schnitzler E. (2014), Thermal, structural and rheological behaviour of native and modified waxy corn starch 
with hydrochloric acid at different temperatures, J. Therm. Anal. Calorim, 115, pp. 1318.

17. Beninca C., Demiate I.M., Lacerda L.G., Carvalho Filho M.A.S., Ionashiro M., Schnitzler E. (2008), Thermal behavior of corn starch granules modified by acid treatment at 30 and $50^{\circ} \mathrm{C}$, Ecletica Quim., 33, pp. 13-18.

18. Liu X., Ma H., Yu L., Chen L., Tong Z., Chen P. (2014a), Thermal-oxidative degradation of high-amylose corn starch, J. Therm. Anal. Calorim., 115, pp. 659-665.

19. Costa F.J.O.G., Leivas C.L., Waszczynsky N., Godoi R.C.B., Helm C.V., Colman T.A.D., Schnitzler, E. (2013), Characterization of native starches of seeds of Araucaria angustifolia from four germplasm collection, Thermochim. Acta., 565, pp. 172-177.

20. Pietrzyk S., Fortuna T., Królikowska K., Rogozínska E., Labanowska M., Kurdziel M. (2013), Effect of mineral elements on physicochemical properties of oxidised starches and generation of free radicals, Carbohydr. Polym. 97, pp. 343-351.

21. Carmona-Garcia R., Sanchez-Rivera M.M., Mendez-Montealvo G., Garza-Montoya B., Bello-Perez L.A. (2009), Effect of the cross-linked reagent type on some morphological, physicochemical and functional characteristics of banana starch (Musa paradisiaca), Carbohydr. Polym., 76, pp. 117-122.

22. Liu J., Wang B., Lin L., Zhang J., Liu W., Xie J., Ding Y. (2014b), Functional, physicochemical properties and structure of cross-linked oxidized maize starch, Food Hydrocolloids, 36, pp. 45-52.

23. Purcell S., Wang Y.J., Seo H.S. (2014), Application of oxidised starch in bake-only chicken nuggets, J. Food Sci., 79, pp. 810-815.

24. Kuakpetoon D., Wang Y.J. (2001), Characterization of different starches oxidized by hypochlorite, Starch/Starkë, 53, pp. 211-218.

25. Zhou F., Liu Q., Zhang H., Chen Q., Kong B. (2016), Potato starch oxidation induced by sodium hypochlorite and its effect on functional properties and digestibility, Int. $J$. Biol. Macromol., 84, pp. 410-417.

26. Spier F., Zavareze E.R., Silva R.M., Elias M.C., Dias A.R.G. (2013), Effect of alkali and oxidative treatments on the physicochemical, pasting, thermal and morphological properties of corn starch, J. Sci. Food Agric., 93, pp. 2331-2337.

27. Marcon M.J.A., Kurtz D.J., Raguzzoni J.C., Delgadillo I., Maraschin M., Soldi V., Reginatto, V., Amante E.R. (2009), Expansion Properties of Sour Cassava Starch (Polvilho Azedo): Variables Related to its Practical Application in Bakery, Starch/Stärke, 61, pp. 716-726

28. Joshi M., Aldred P., McKinight S., Panozzo J.F., Kasapis S., Adhikari R., Adhukari, B. (2013), Physicochemical and functional characteristics of lentil starch, Carbohydr. Polym., 92, pp. 1484-1496. 